\title{
ECONOMÍA POPULAR Y ORGANIZACIÓN SOCIAL
}

\section{POPULAR ECONOMY AND SOCIAL ORGANIZATION}

Licda. María Fernanda Arguedas Abarca

Editora

En el Tema Central titulado "ECONOMía POPULAR Y ORGANIZACIÓN SOciaL", Sobrado y Rojas presentan una reflexión enfocada al análisis del Estado clientelista, sus repercusiones para la sociedad civil y la relevancia de la organización autónoma de las comunidades. Actualmente, en los países latinoamericanos se presenta un rezago económico y una manipulación ideológica enfocada a intereses particulares, al mismo tiempo que aumenta los niveles de pobreza, la delincuencia organizada y el desempleo. Esto ha significado una división de la sociedad civil y un alto grado de incertidumbre en las posibles soluciones a futuro. Por esta razón, se propone una experiencia centrada en la educación de las personas dentro de un proceso organizacional de actividades que transformen la cultura, pero que no sea solamente desde un enfoque asistencialista. Esta organización autónoma a través de una capacitación en organización cívica y empresarial de las personas, impulsaría el empoderamiento ciudadano y contribuiría a la formación del capital social para el desarrollo sostenible de los países latinoamericanos.

Palumbo realiza un análisis teórico de la economía popular argentina, a partir de un estudio de las dinámicas de construcción de la subjetividad colectiva de los trabajadores en la CTEP en el Área Metropolitana de Buenos Aires, Argentina. Asimismo, se dimensiona el caso de la informalidad en algunos países de América Latina. Para esta reflexión toma como base la lectura poscolonial del político y antropólogo indio Partha Chatterjee, quien considera tres dimensiones de la economía popular en la informalidad: las prácticas cotidianas, los sujetos y la construcción de demandas por derechos. Este autor denota la importancia de la focalización en la política popular urbana, la mirada realista y la politicidad intrínseca en la micropolítica cotidiana; al mismo tiempo, señala que los gobernados hacen política con lo cual pueden cuestionar sus términos, el derecho, la estatalidad y la democracia.

Desde México, Rendón-Morquecho y Marroquín-Arreola hacen un estudio sobre el efecto de la desigualdad del ingreso en el crecimiento económico de las 32 entidades federativas del país entre los años 2008-2016. Para ello se utilizó un modelo econométrico de datos panel utilizando las variables del modelo de Cingano (2014): Producto Interno Bruto per cápita, la matrícula escolar, la formación bruta de capital fijo y el coeficiente de Gini. Se encontró una relación inversa entre crecimiento y desigualdad, lo cual demuestra la importancia de implementar políticas sociales y económicas enfocadas en una mejor redistribución del ingreso de la población. 
En la contribución de Bojórquez y Leyva, se analizan las estrategias utilizadas por las autoridades municipales de Culiacán, apoyadas por el gobierno del Estado de Sinaloa (México), para reducir el alto índice de inseguridad (robos, asaltos, homicidios, entre otros delitos) en el año 1994. Las autoridades expresaron sus intenciones de regular los horarios de circulación, la vestimenta y la forma de portar la cabellera de la población joven. Por medio del análisis de la literatura y los periódicos de la época se evidencia la confrontación y el debate que surgió debido a esta propuesta, involucrando a amplios sectores de la población: autoridades municipales, las personas jóvenes, la iglesia, abogados, defensores de los derechos humanos, partidos políticos, entre otros. Se estigmatizó a la población joven como peligrosa, responsable de la problemática de inseguridad que pone en peligro el orden social. No obstante, este sector de la población se organizó y convocó a las autoridades responsables para defender sus derechos $y$ hacer nuevas propuestas enfocadas a reducir la inseguridad.

En el artículo de Aranda, se expone las crisis económicas de los años 1929 y 2008 en España, así como su relación con el exceso de volumen comercial debido a una acelerada producción constante. Lo anterior conllevo a una inestabilidad comercial que provocó recortes salariales $y$ despidos masivos de las empresas, creando grandes endeudamientos en las economías familiares. En los tiempos modernos se debe buscar un equilibrio entre la organización social y el desarrollo tecnológico, que logre solventar los intereses de todas las partes de la sociedad en un mundo global real basado en el equilibrio social. Sin embargo, el capitalismo global no se autorregula, con lo cual surge un desequilibrio comercial que incita a perder el valor real de los productos, el debilitamiento de la economía doméstica y el empobrecimiento del Estado.

En la sección de ARTículos, Cuevas presenta un conjunto de reflexiones sobre el proyecto "Promoción de la Salud Sexual, prevención $y$ detección del viH en personas jóvenes del Gran Área Metropolitana de Costa Rica” realizado por la Asociación Demográfica Costarricense en el año 2017. El objetivo de este proyecto consistió en capacitar por medio de talleres participativos a la población joven de colegios nocturnos en los cantones de mayor incidencia del VIH con el fin de disminuir la vulnerabilidad de contagio. Se evidencia sobre la posibilidad de impactar directamente en las poblaciones con proyectos desde políticas públicas enfocadas a los derechos sexuales y reproductivos, así como el reto de ampliar la educación sexual a otros ámbitos con perspectiva de género sobrepasando los discursos hegemónicos presentes.

Gallegos realiza una propuesta de una nueva visión de la guerra desde un punto de vista sociológico, ya que los cambios políticos, culturales y sociales derivan en diferentes puntos relevantes que las ciencias sociales deben estudiar, como por ejemplo, la desaparición del Estado como actor principal, los avances tecnológicos, los nuevos actores (rebeldes o fuerzas no estatales y empresas privadas), el terrorismo, la generalización del ataque a civiles, las nuevas coordenadas de tiempo y espacio. En este artículo, se consideraran dos herramientas conceptuales y metodológicas provenientes del campo de la Sociología de la guerra: 
guerra asimétrica y guerra difusa. Para este estudio se tomo como referencia al sociólogo argentino Flabián Nievas, quien propone las herramientas necesarias para comprender la Sociología de la guerra. Asimismo, en su libro expone que la guerra es vista desde una perspectiva antropológica (la naturaleza humana es intrínsecamente violenta) y desde la estructura interna del Estado. Sin embargo, para el estudio de las guerras actuales resultan incompletas, ya que no consideran las particularidades en cada caso. Además, se expone la visión napoleónica que las personas tienen de la guerra y la idea de que son conflictos sociales que pasan solamente en otras naciones.

En el campo de la migración, Dolores analiza las motivaciones de las personas migrantes venezolanas que se trasladaban hacia el aglomerado Santa Rosa-Toay (La Pampa), Argentina, entre los años 2010-2019. Se identificaron cuatro olas migratorias: 1) luego de la asunción del presidente Hugo Chávez Frías, compuesta por profesionales de clase alta e investigadores, 2) a partir del año 2007, estuvo conformada por personas ciudadanas pertenecientes a las clases medias y altas, profesionales y empresarios, 3) con la asunción del presidente Nicolás Maduro en el año 2013, estuvo compuesta por personas ciudadanas de clase media, en su mayoría con estudios universitarios y terciarios $y$,4) desde el año 2016, conformada por personas ciudadanas de clase media y baja. Para el análisis de las motivaciones, se realizaron entrevistas a profundidad a diferentes migrantes con el fin de conocer los factores de expulsión, la percepción de vulnerabilidad o persecución, el deseo de regresar a su país y la reunificación familiar. Se concluyó que las motivaciones para migrar se explicaban por las privaciones esenciales en su país de origen: alimentos, medicina, servicios básicos e higiene. Asimismo, debido a los actos delictivos y violencia que sufrían, las personas salían a buscar un lugar más seguro para vivir.

Blanco, Corea y Rodríguez, en su estudio relacionan el consumo de sustancias psicoactivas como estrategia para afrontar el estrés, la ansiedad y la depresión en el caso de las mujeres trabajadoras sexuales en Costa Rica. Para ello, se contó con el apoyo de la la Asociación La Sala, la cual es una organización no gubernamental que busca el reconocimiento de los derechos de esta población y el mejoramiento de su calidad de vida. Con el estudio se pudo evidenciar que las sustancias de mayor prevalencia son las bebidas alcohólicas y la cocaína, y que el factor económico y de salud (contraer alguna enfermedad venérea) son los mayores detonantes de estrés.

En el ámbito las relaciones públicas, los profesores García, Gonzáles y Ortiz presentan un interesante caso sobre la disputa territorial del río Bravo entre México y Estados Unidos a través del Tratado de 1944, con la finalidad de ejemplificar la relevancia de la diplomacia del agua a nivel mundial, la cual tiene el objetivo de buscar la cooperación conjunta y prevenir conflictos concernientes a los recursos hídricos para conservar la seguridad y la estabilidad regional. En el acuerdo del río Bravo toma relevancia la Comisión Internacional de Límites y Aguas entre México y Estados Unidos, la cual se encontraba dotada del carácter que tiene un organismo internacional y cada gobierno debió reconocer su carácter 
diplomático. De esta manera, se logró una negociación acorde a los intereses de ambas partes y con las líneas de acción en caso de diferentes situaciones que podrían presentarse en el futuro

En la colaboración de Urbina, se exponen las posiciones y los discursos de los periódicos La República y el Eco Católico, respecto a la celebración del primero de mayo durante el periodo 1956-1980. Se busca evidenciar la influencia política e ideológica que la prensa escrita ejercía sobre la población costarricense en este periodo de tiempo. Se revela una posición moral-conservadora que invisibilizaba la explotación laboral, además de señalar la fecha como la festividad de la rendición de William Walker. Asimismo, se realizó una celebración aparte a la organizada por grupos sindicales, en oposición a los grupos comunistas y los simpatizantes de izquierda, a quienes se consideraba como el enemigo común de todo buen demócrata cristiano y pacifista. La estrategia utilizada se basaba en la difamación, el adoctrinamiento, la ideologización planificada, y la represión a los partidos, sindicatos y trabajadores.

Desde España, se cuenta con el artículo de Santos y Camacho, quienes estudiaron el tratamiento de la temática del suicidio en diversos periódicos españoles (La Razón, El Mundo, El País y ABC ) durante el año 2017. Es importante denotar el papel de la Organización Mundial de la Salud al elaborar guías con directrices para la prevención del suicidio dirigidas a profesionales de los medios de comunicación, enfocándose en no tratar al suicidio de forma sensacionalista, no glorificar a la persona que se suicida ni verlo como solución a los problemas, entre otras recomendaciones. En el caso en estudio se demuestra un tratamiento del tema sumamente descriptivo, sin profundización científica o profesional, predominando las fuentes institucionales y policiales. La temática predominante es el suicidio como acto consumado, seguido de cultura, tentativa e inducción al suicidio y legislación. No se aborda el tema de manera informativa, es decir, prevención del suicidio, formas para superar las conductas suicidas o lugares para buscar ayuda. En resumen, no se siguen los lineamientos ni recomendaciones de la Organización Mundial de la Salud.

Para finalizar, Medina realiza un aporte metodológico a la temática de derechos humanos, al presentar la validez de contenido de un instrumento de medición de derechos humanos en México. A partir de literatura especializada y detallando 45 de los 56 derechos humanos según la página oficial de la $\mathrm{CNDH}$, se obtuvieron 322 ítems que integran el instrumento. Para obtener la validez de contenido, se aplicó el método de panel de expertos utilizando el modelo desarrollado por Lawshe (1975) y modificado por Tristán (2008), llegando a un resultado aceptable para que el instrumento sea utilizado en futuras investigaciones. 